\title{
Association of Vitamin D Supplementation in Cardiorespiratory Fitness and Muscle Strength in Adult Twins: A Randomized Controlled Trial
}

Jeane Pires ( $\square$ jeanefpires@hotmail.com )

Federal University of Rio Grande do Norte https://orcid.org/0000-0003-0473-3714

Michelle Vasconcelos de Oliveira Borges

UFRN: Universidade Federal do Rio Grande do Norte

Aline Alves Soares

UFRN: Universidade Federal do Rio Grande do Norte

Elys Costa de Sousa

UFRN: Universidade Federal do Rio Grande do Norte

José Ronaldo Ribeiro da Costa

UFRN: Universidade Federal do Rio Grande do Norte

Weberthon Alessanderson Costa Silva

UFRN: Universidade Federal do Rio Grande do Norte

Magnus Vinícius Bezerra de Sousa

UFRN: Universidade Federal do Rio Grande do Norte

Paulo Moreira Silva Dantas

UFRN: Universidade Federal do Rio Grande do Norte

Vivian Nogueira Silbiger

UFRN: Universidade Federal do Rio Grande do Norte

André Ducati Luchessi

UFRN: Universidade Federal do Rio Grande do Norte

Original Research Article

Keywords: vitamin D, cardiorespiratory fitness, muscle strength, upper limb muscle strength

Posted Date: December 1st, 2020

DOl: https://doi.org/10.21203/rs.3.rs-116070/v1

License: (c) (1) This work is licensed under a Creative Commons Attribution 4.0 International License.

Read Full License 


\section{Abstract}

Background: Although vitamin D is related to cardiorespiratory fitness and muscle strength, there is no evidence in the literature about the genetic influence of the response to the increase in body vitamin D. Therefore, we evaluate the effect of longitudinal supplementation of vitamin D on parameters of physical fitness in monozygotic twins.

Methods: In total, 74 participants were included, with a mean age of 25 years, divided into two groups, one group received supplementation with cholecalciferol for 60 days and the other group did not. Cardiorespiratory fitness and muscle strength were measured before and after supplementation, through maximal treadmill tests and dynamometry, respectively. Wilcoxon tests were used to compare intra-group results and the Mann-Whitney test to examine intergroup differences.

Results: There was an increase in the serum concentration of vitamin D in participants who ingested the supplementation. Cardiorespiratory fitness improved after supplementation through increases in the values of maximum oxygen consumption of $28 \%(\mathrm{P}<0.001)$. Muscle strength in right hand grip significantly increased in participants who received the supplement to $33.0(P=0.007)$.

Conclusion: 60 days of cholecalciferol supplementation improved cardiorespiratory fitness and upper limb muscle strength.

Trial registration: RBR-3qy2f2. Registered 28 March 2016, http://www.ensaiosclinicos.gov.br/rg/RBR3qy $2 f 2 / 2$

\section{Key Points}

- Our work is innovative for using twin siblings in a clinical trial, decreasing the genetic differences between the control and intervention groups. Each pair of twins of the same sex was divided and one identical sibling was allocated to the control group and the other to the intervention group. Twins of different sexes were not included, only female sibling pairs or male sibling pairs.

- Supplementation with 2000 IU cholecalciferol for only 60 days generated benefits in cardiorespiratory fitness and muscle strength, by significantly increasing the Maximum Oxygen Consumption and the right hand grip.

\section{Introduction}

Vitamin D is involved in several non-skeletal functions, playing an important role in immunity and in cardiopulmonary and muscle functions [1]. Vitamin D receptors are present in several types of cells, including skeletal muscle, heart muscle, and vascular smooth muscle [2]. Thus, vitamin D insufficiency has been shown to be related to muscle weakness, arterial thickening, myocardial hypertrophy, and hypertension $[3,4]$. 
Aerobic capacity measured through Maximum Oxygen Consumption $\left(\mathrm{VO}_{2} \mathrm{max}\right)$, has been widely used in studies as a good indicator of cardiovascular condition [5, 6]. Low levels of cardiorespiratory fitness have been associated with health and quality of life problems, such as lower longevity, lower disposition, higher body fat content, worse lipid profile, and disturbances in glucose metabolism [7]. Thus, better cardiorespiratory fitness can reduce the risk of death from cardiovascular and metabolic diseases [8, 9].

There is significant evidence that vitamin $D$ is an influential factor for $\mathrm{VO}_{2} \max [10,11,12]$. However, the majority of studies on this theme are observational, raising the question as to whether the serum concentration of 25-hydroxyvitamin $\mathrm{D}(25(\mathrm{OH}) \mathrm{D})$ is a cause of increased $\mathrm{VO}_{2}$ max or simply a result with little significance [13]. This increases the importance of clinical trials that help elucidate the relationship between vitamin $\mathrm{D}$ and $\mathrm{VO}_{2} \max [14]$.

It is also known that vitamin D affects muscle strength, muscle size, and neuromuscular performance [15, 16] and the reduction in muscle strength and power also impairs the quality of life of individuals, as these factors influence the functional capacity to perform basic activities of daily life, generating limitations for their execution [17].

Both VO2max and muscle strength are influenced by genetic factors [18] and the only human study model that enables control of the genetic factor is the study of monozygotic twins (MZ). MZ twins develop from a single egg cell, giving rise to two individuals who share the same genetic load and, because they have the same genotype, the differences between them occur mainly due to the external influences of the environment where they are inserted; the greater the differences in these influences, the greater the probabilities of different phenotypic observations. Thus, the realization of a study with twins enables analysis of the influence on the phenotype through the isolation of the interference of the genetic factor [25], in the case of the current study, the divergent external influence will be vitamin D supplementation. Thus, clinical trials with MZ allow control of one of these factors, making them extremely relevant [19].

Therefore, knowing the relationship of vitamin D with cardiorespiratory fitness and muscle strength, we aimed to establish whether low doses of this nutrient would bring improvements to the health of individuals. Therefore, the aim of this study is to evaluate the effect of cholecalciferol supplementation on cardiorespiratory fitness and muscle strength in healthy adult MZ twins.

\section{Methods}

\section{Study Population and Randomization}

In total, 74 men and women volunteer MZ twins participated in the study. To obtain a statistical power of 0.958, using the values of Mean and Standard Deviation, at least 25 individuals were required before supplementation and 25 individuals after supplementation. Zygosity in twins was determined using a validated zygosity questionnaire with $93.3 \%$ accuracy [20]. This was a randomized clinical trial by lot, performed by the researcher responsible, which took place between 2016 and 2018, where each pair of 
twins was separated, with one twin allocated to the control group (CG, without intervention) and the other to the supplemented group (SG, with intervention) (Fig 1). All analyses were performed on the first day of inclusion in the research (T0) and after 60 days of supplementation (T60).

Eligibility criteria included twins of the same sex, from 18 to 40 years of age, with no diagnosis of any chronic non-communicable disease, non-obese, without dyslipidemia, and non-smokers. The exclusion criteria included individuals who could not perform the physical tests, who were users of illicit drugs, and those using energy or protein supplements, or supplements containing vitamin $D$, pregnant women, nursing mothers, and patients with metallic implants and pacemakers

The twins included in the SG consumed 1 oily capsule of cholecalciferol per day, with a concentration of $2.000 \mathrm{IU}$, for a period of 60 days in the morning. This concentration does not exceed the maximum tolerable daily intake limit (UL), which is $4.000 \mathrm{IU} /$ day [21], in addition to being considered a dose for maintaining adequate levels of vitamin $D$ in individuals after treatment for deficiency of this nutrient. All participants in the SG received a follow-up form to daily record when they ingested the capsule. Sixty days after the start of supplementation, these forms were returned to the researchers, for monitoring compliance. The researchers responsible for conducting physical tests and blood collection did not know which group the individual was included in, the CG or SG.

During the intervention period, the twins in the CG and SG maintained their usual routine, without dietary, sports, or lifestyle changes. After 30 days of inclusion in the study, participants from the SG group were interviewed to confirm appropriate capsule intake and participants from both groups were interviewed to confirm maintenance of their routine.

At T0 and T60, all participants in the CG and SG groups performed collection of peripheral blood samples after a 12-hour fast, on a different day from the physical tests. The chemiluminescence technique (Access 2, Beckman Coulter, United States) was used to measure $25(\mathrm{OH}) \mathrm{D}$ in serum. Values below 20 $\mathrm{ng} / \mathrm{mL}$ were considered as deficiency [22].

At the beginning of the research, the primary endpoint was considered as the change in the serum concentration of $25(\mathrm{OH}) \mathrm{D}$ after 60 days of supplementation with cholecalciferol. Our secondary endpoint was the variation in physical fitness after 60 days of cholecalciferol supplementation.

\section{Determination of Muscle strength:}

Isometric strength of the upper limbs was evaluated through dynamometry to determine muscle strength, using the handgrip and scapular strength test. The handgrip test followed the recommendations of the American Society of Hand Therapists, where the subject remained seated comfortably, positioned with the elbow at $90^{\circ}$, the forearm in a neutral position, and the wrist in a position varying from $0^{\circ}$ to $30^{\circ}$ of extension [23], using a hydraulic dynamometer (JAMARß, precision of 0.2 kilogram-force - $k g f)$. All subjects received verbal commands to perform the test, with standardized instructions. The test always started on the right side. 
The recorded value of each individual was the highest value among the three measurements, performed alternately between the hands, with 5 seconds of maximum contraction in each handgrip and $60 \mathrm{a}$ second rest between the measurements.

Scapular strength was measured using a $50 \mathrm{kgf}$ Crow ${ }^{\circledR}$ scapular dynamometer. Each participant, standing, with their feet in an anatomical position, held the dynamometer at chest level, without touching the chest, with their elbows open and parallel to the ground. At the command of the evaluator, the participant performed a maximum scapular contraction lasting 3 to 5 seconds, with three repetitions, and an interval of 60 seconds between them. The highest value between attempts was considered as the result.

\section{Determination of Cardiorespiratory Fitness}

To determine maximum oxygen consumption, the cardiopulmonary stress test was performed (TECP) on a Cortex ergospirometer (Metalyzer ${ }^{\circledR} 3 \mathrm{~B}$ ), following a treadmill ramp protocol. Progressive and continuous speed and inclination increments were applied, according to the individual capacity estimated for each participant, based on the American College of Sports Medicine (ACSM) [24], and aiming to achieve absolute and relative $\mathrm{VO}_{2} \mathrm{max}$ in a test period of 8 to 12 minutes [5]. An initial speed and incline pattern was adopted for sedentary and active individuals, $3 \mathrm{~km} / \mathrm{h}$ and $0 \%$ incline and $4 \mathrm{~km} / \mathrm{h}$ and $0 \%$ incline, respectively. The final speed and incline were determined according to the following prediction formulas, considering walking for sedentary and running for active individuals [24]:

$$
\begin{aligned}
& 1-\text { Walking } \rightarrow \mathrm{VO}^{2}=\text { Speed } .1 .675+0.3015 . \text { Speed. Incline }+3.50 \\
& 2-\text { Running } \rightarrow \mathrm{VO}^{2}=\text { Speed } .3,35+0.15075 . \text { Speed. Incline }+3.50 .
\end{aligned}
$$

Oxygen consumption was continuously recorded during the TECP $\left(\mathrm{VO}_{2}\right)$ as well as the respiratory exchange ratio (RER), breath by breath, through analysis of pulmonary gas exchange (metabolic analyzer Metalyzer ${ }^{\circledR} 3 \mathrm{~B}$ ). The equipment was calibrated prior to the development of the research and at the beginning of each TECP through self-calibration.

\section{Statistical Analysis}

The statistical software IBM SPSS version 20.0 for Windows (SPSS Inc., Chicago, IL, USA) was used for all analyses. The Kolmogorov-Smirnov test was used to assess the distribution of variables, which presented non-parametric distribution. Categorical variables are shown as number (percentage) and compared by the Chi-square test. Continuous variables are shown as median (minimum and maximum). The differences between the medians of vitamin D, cardiorespiratory fitness, and muscle strength of the CG and SG groups were assessed by the Mann-Whitney test and the Wilcoxon test was used to evaluate the differences in the median intragroup values of the CG and SG between T0 and T60. All differences were considered significant when $p \leq 0.05$. 


\section{Ethics}

This study was approved by the Brazilian Registry of Clinical Trials under code RBR-3qy2f2 (05/09/2017) and the Research Ethics Committee of the Federal University of Rio Grande do Norte (UFRN), protocol number 1.385.218, CAAE 51186615.5.0000.5292.

\section{Results}

All 74 twins, 54 female and 20 male, with an average age of 25 years, completed the study, with 37 individuals in the CG and 37 individuals in the SG. The BMI $\left(\mathrm{kg} / \mathrm{m}^{2}\right)$ of the CG was 25.2 and of the SG 24.9 , with no differences between groups $(p=0.798)$ at T0 and T60. All SG individuals ingested $100 \%$ of the capsules provided. Family income, training frequency, and training duration were similar between the CG and SG (Table 1).

Vitamin D concentration in the SG twins increased $70 \%$ after 60 days of consuming $2000 \mathrm{IU}$ cholecalciferol daily $(T 0=30.00 \mathrm{ng} / \mathrm{mL}$ and $\mathrm{T} 60=50.87 \mathrm{ng} / \mathrm{mL} p<0.001)$. In the CG there was no variation in this concentration ( $\mathrm{T} 0=30.02 \mathrm{ng} / \mathrm{mL}$ and $\mathrm{T} 60=31.81 \mathrm{ng} / \mathrm{mL} p=0.950)$. At T0 there were no differences between the CG and SG $(p=0.189)$. No subject presented potentially toxic concentrations of 25-hydroxy-vitamin D.

Cardiorespiratory fitness and muscle strength presented no differences between the CG and SG at T0. However, at T60, absolute $\mathrm{VO}_{2}$ max was different between the CG and SG ( $\left.p<0.015\right)$, since after supplementation, at $\mathrm{T} 60$, absolute $\mathrm{VO}_{2}$ max increased by $28 \%$ in the $\mathrm{SG}(p<0.001)$. All subjects maintained their usual routine during the two months of participation in the study, including the level of physical exercise, which can be confirmed by the lack of variation in RER in both groups (Table 2).

Muscle strength of the left arm also increased in the SG after supplementation $(p=0.007)$ (Table 2). It should be noted that only 1 individual in each group used their left hand as predominant, the others used their right hand for writing and other tasks.

\section{Discussion}

In this clinical trial with healthy male and female MZ twins, we found that vitamin D supplementation for two months improved cardiorespiratory fitness and muscle strength by increasing the $\mathrm{VO}_{2}$ max and manual strength of the left arm.

To the best of our knowledge, this is the first study to explore the links between vitamin D supplementation and cardiorespiratory fitness in MZ twins. We chose to work with $M Z$ twins to reduce the genotypic differences in phenotypic responses, since each $\mathrm{MZ}$ pair comes from a single zygote and they present genetically identical elements [25]. 
We observed alterations in oxygen consumption in the group that received supplementation, through improvement in absolute VO2max, however, when considering body mass we did not find significant changes in relative VO2 max, suggesting that regardless of genetics, absolute VO2max can be modified by healthy eating habits and possibly by an increase in serum vitamin $D$.

This occurs because absolute VO2max is less influenced by genetics when compared to relative VO2max [26], so, as our study used monozygotic twins, we evidenced that genetics were decisive for responding to our external factor, in this case, supplementation. However, we did notice a slight increase in the 75th percentile of the supplemented group in relation to the relative VO2 max, which could be a possible indication that this supplementation can alter the relative VO2 max if used in larger doses or for a longer period of time. Thus, further research on the topic with $M Z$ twins is needed to complement this study.

The hereditary and environmental contribution to biochemical, anthropometric, and functional markers as risk indicators for physical health, has been observed in studies on heritability $[27,28]$. These studies aim to understand the relative influence of genotype and environment on phenotypic variation. Tarnoki [29] suggests that studies with twins may reveal genetic alterations, which are not clearly manifested, associated with biomarkers.

Cardiorespiratory fitness is recognized as a central determinant of survival in healthy individuals or those with comorbidities [30,31]. Low fitness has been proposed as a new modifiable marker to improve risk stratification [30], since risk factors tend to group in sedentary people, regardless of age and sex [32].

In view of the increase in cardiovascular disorders, there is a need to investigate efforts to prevent and screen cardiovascular risk factors. In addition, good cardiorespiratory fitness is a predictor of life expectancy, both in patients with or without heart disease [33].

Pitz et al.[34] demonstrated the existence of a direct and indirect action of vitamin D on the function of cardiomyocytes and morphology of the heart, since low levels of vitamin D were associated with a higher prevalence of myocardial dysfunction. Gallagher and collaborators [35] showed that vitamin D can improve aerobic performance through indirect action on $\mathrm{VO}_{2} \mathrm{max}$. This corroborates with our results, since an increase in blood levels of $25(\mathrm{OH}) \mathrm{D}$ was observed, increasing the maximum volume of oxygen captured and taken to the tissues through the cardiovascular system for energy production, in a unit of time.

It is possible that vitamin $D$ contributed to this increase due to the greater expression of the vitamin $D$ receptor (VDR) existing in several cells that make up the cardiovascular system, actively participating in cardiac function, through the regulation of muscle cell growth and the degree of myocardial contractility, among others $[36,37]$.

Vitamin D participates in cellular mechanisms that act on muscle growth and strength [35], being important for maintaining the mass, strength, and speed of contraction of skeletal muscle [38]. In this sense, vitamin $D$ is considered fundamental for muscle quality and strength production [39], and its 
deficiency has been related to decreases in these factors and in muscle mass [40], with impaired balance and an increased incidence of falls, which can cause irreversible functional limitations $[41,42,43]$.

Greater muscle strength may also be associated with better health and cardiovascular protection [44], a lower incidence of cardiovascular disease, and lower risk of all-cause mortality $[45,46,47]$.

Thus, vitamin $D$ supplementation has been gaining prominence as a strategy to control physical fitness, including muscle strength $[48,49]$. However, as the majority of studies were carried out in older adults or athletes $[41,50,1]$, the possible benefits that may exist from vitamin D supplementation in healthy nonathlete adults are not yet known.

Zhu et al., [51] after supplementing 302 older women, aged between 70 and 90 years, who were deficient in vitamin $D$, with $1,000 \mathrm{lU} /$ day for one year, concluded that the association of vitamin $D$ with calcium for supplementation is used for improving muscle strength and mobility. Supplementation with $1,000 \mathrm{IU} /$ day of vitamin $D$ alone for nine months in 160 postmenopausal women with a mean age of 58 years showed a significant increase in muscle strength in the lower limbs through the sit and stand test [52].

Handgrip dynamometry is often used for functional and nutritional assessment of healthy and pathological individuals, not only to measure hand strength, but to assess total body strength $[53,54]$ and the nutritional status of pre and post-surgical patients $[55,56,57]$. Handgrip dynamometry is an inexpensive method, which is easy to use, and its results are well accepted in research and clinical evaluations $[58,59]$.

Our results indicate a possible benefit of the increase in the serum concentration of vitamin $D$ in the long term, since after only two months of supplementation in low concentration, it was possible to observe a slight increase in manual strength of the non-dominant arm in SG, and only one individual used the left hand as the dominant hand. Dominance is an individual factor that significantly influences the measurement of manual dynamometry [60], as the dominant hand has higher handgrip strength values than the non-dominant hand [61, 62]. It is possible that in the long run, this increase is most likely to bring about more significant improvements in muscle strength.

The differences observed in both sexes between the strength of the dominant and non-dominant hand is usually around $10 \%$ [62]; the dominant hand being the one with the best performance and the most strength [63]. This fact may have contributed to the increase in strength only of the non-dominant hand, since this gain was probably not due to training with a load higher than that performed on a daily basis, but due to the supplementation which increased the serum vitamin D concentration and probably contributed to this strength improvement, since there were no changes in lifestyle or training during the intervention period. This occurs because the vitamin D receptor (VDR) is found in skeletal muscle cells, and vitamin $D$ is important for maintaining the mass, strength, and speed of contraction of this muscle, due to its actions on the regulation of calcium transport, synthesis protein, and kinetics of contraction [64]. 
It is possible to conclude that vitamin $\mathrm{D}$ has beneficial effects on physical fitness, improving $\mathrm{VO}_{2} \mathrm{max}$ and increasing manual muscle strength. However, better clarification of the molecular mechanisms of this role of vitamin $\mathrm{D}$ in improving skeletal and cardiorespiratory muscles is necessary.

\section{Study Limitations}

The main limitation of this study was the low sample size, since we selected a very restricted study population, MZ twins, to better assess the influence of the environmental factor, and the greater proportion of women in relation to men. Another point was the use of only one concentration of supplement and the evaluation carried out at only one time point after supplementation, two months, without further analysis and evaluation of these long-term findings. Therefore, for future research we suggest increasing the sample number and evaluating different concentrations of supplementation with different times of use.

\section{Conclusion}

Increasing the serum concentration of vitamin $D$ to values above 50 generates health benefits, improving cardiorespiratory fitness and slightly increasing muscle strength of the non-dominant hand. Our findings contribute to the growing evidence regarding the non-skeletal benefits of vitamin $D$.

\section{Abbreviations}

V02max: Maximum Oxygen Consumption

$25(\mathrm{OH})$ D:25-hydroxyvitamin D

MZ: Monozygotic twins

CG: Control group

SG: Supplemented group

T0: first day of inclusion in the research

T60: after 60 days of supplementation

UL: Maximum tolerable daily intake limit

IU: International unity

Kgf: Kilogram-force

TECP: Cardiopulmonary stress test was performed 
ACSM: American College of Sports Medicine

RER: Respiratory exchange ratio

UFRN: Federal University of Rio Grande do Norte

\section{Declarations}

\section{Availability of data and materials}

The additional datasets generated they are with corresponding author available on reasonable request.

\section{Acknowledgements}

We would like to thank the Coordination for the Improvement of Higher Education Personnel - Brazil (CAPES).

\section{- Funding}

This study did not receive any funding.

\section{- Ethical Approval and Consent to participate}

This work was approved by the Research Ethics Committee of the Federal University of Rio Grande do Norte and the Brazilian Registry of Clinical Trials. All participants signed a written informed consent. The study was performed in accordance with the standards of ethics outlined in the Declaration of Helsinki.

\section{- Consent for publication}

All authors made revisions to the manuscript, and have read and approved the final version.

\section{- Competing interests}

All authors declare no support from any organization for the submitted work, no financial relationships with any organizations that might have an interest in the submitted work, and no other relationships or activities that could appear to have influenced the submitted work.

\section{- Authors' contributions}

Conception and design of the study: JFPM and ADL. Investigation and methodology of the study, drafting the work: JFPM, MVOB, ADL, and VNS. Acquisition and analysis of data and revision of the work: JFPM, MVOB, AAS, ECS, JRRC, WACS, MVBS, PMSD, VNS, and ADL.

\section{- Corresponding author}

Correspondence to Jeane Franco Pires Medeiros. 
- Authors' information

\section{Affiliations:}

Department of Health Sciences, Federal University of Rio Grande do Norte, Natal, RN, Brazil

Jeane Franco Pires Medeiros, Michelle Vasconcelos de Oliveira Borges, Aline Alves Soares, Weberthon Alessanderson Costa Silva, Paulo Moreira Silva Dantas and André Ducati Luchessi.

\section{Department of Physical Education, Federal University of Rio Grande do Norte, Natal, RN, Brazil}

Elys Costa de Sousa, José Ronaldo Ribeiro da Costa, Magnus Vinícius Bezerra de Sousa and Paulo Moreira Silva Dantas.

Department of Pharmaceutical Sciences, Faculty of Pharmacy, Federal University of Rio Grande do Norte, Natal, RN, Brazil and Department of Clinical and Toxicological Analyses, Federal University of Rio Grande do Norte, Natal, RN, Brazil

Vivian Nogueira Silbiger and André Ducati Luchessi.

\section{References}

1. Todd JJ, Pourshahidi LK, McSorley EM, Madigan SM, Magee PJ. Vitamin D: recent advances and implications for athletes. Sports Med. 2015;45(2):213-219.

2. Bouillon R, Carmeliet G, Verlinden L, Van Etten E, Verstuyf A, Luderer HF, Demay M. Vitamin D and human health: lessons from vitamin D receptor null mice. Endocr Rev. 2008;29(6), 726-776.

3. Pilz S, Henry RM, Snijder MB, et al. Vitamin D deficiency and myocardial structure and function in older men and women: the Hoorn study. J Endocrinol Invest. 2010;33(9):612-617.

4. Beaudart C, Buckinx F, Rabenda V, et al. The effects of vitamin D on skeletal muscle strength, muscle mass, and muscle power: a systematic review and meta-analysis of randomized controlled trials. J ClinEndocrinolMetab. 2014;99(11):4336-4345.

5. Guazzi M, Arena R, Halle M, Piepoli MF, Myers J, Lavie CJ. Focused update: clinical recommendations for cardiopulmonary exercise testing data assessment in specific patient populations. Eur Heart J. 2016;133:694 -711.

6. Miyamoto-Mikami E, Zempo H, Fuku N, Kikuchi N, Miyachi M, Murakami H. Heritability estimates of endurance-related phenotypes: A systematic review and meta-analysis. Scand J Med Sci Sports. 2018;28(3), 834-845. 
7. Bathgate KE, Bagley JR, Jo E, Talmadge RJ, Tobias IS, Brown LE, Galpin AJ. Muscle health and performance in monozygotic twins with 30 years of discordant exercise habits. Eur. J. Appl. Physiol. 2018;118(10), 2097-2110.

8. Kraus WE, et al. Effects of the amount and intensity of exercise on plasma lipoproteins. N Engl $J$ Med. 2002;347(19), 1483-92.

9. Manson JE, et al. Walking compared with vigorous exercise for the prevention of cardiovascular events in women. N Engl J Med. 2002;347, 716-25.

10. Toxqui L, Pérez-Granados AM, Blanco-Rojo R, Wright I, González-Vizcayno C, Vaquero MP. Effects of an iron or iron and vitamin D-fortifed favored skim milk on iron metabolism: a randomized controlled double-blind trial in iron-defcient women. J Am CollNutr. 2013;32(5), 312-320.

11. Bacchetta J, Zaritsky JJ, Sea JL, Chun RF, Lisse TS, Zavala K, et al. Suppression of iron-regulatory hepcidin by vitamin D. J Am SocNephrol. 2014;25(3), 564-572.

12. Zughaier SM, Alvarez JA, Sloan JH, Konrad RJ, Tangpricha V. The role of vitamin $D$ in regulating the iron-hepcidin-ferroportin axis in monocytes. J ClinTransIEndocrinol. 2014;1(1), 19-25.

13. Autier P, Boniol M, Pizot C, Mullie P. Vitamin D status and ill health: a systematic review. Lancet Diabetes Endocrinol. 2014;2(1), 76-89.

14. Marawa A, Kurbanova N, Qayyum R. Association between serum vitamin D levels and cardiorespiratory fitness in the adult population of the USA. Eur. J. Prev. Cardiol. 2019;26(7), 750-755.

15. Rosen CJ, Adams JS, Bikle DD, Black DM, Demay MB, Manson JE, et al. The nonskeletal effects of vitamin D: an Endocrine Society scientific statement. Endocrine Rev. 2012;33, 456-492.

16. Levin GP, Robinson-Cohen C, de Boer IH, Houston DK, Lohman K, Liu Y, et al. Genetic variants and associations of 25 -hydroxyvitamin $\mathrm{D}$ concentrations with major clinical outcomes. JAMA. 2012;308(18), 1898-1905.

17. Silva NA, Menezes TN, Melo RLP, Pedraza DF. Handgrip strength and flexibility and their relationship with anthropometric variables in the elderly. Brazilian Medical Association Magazine. 2013;59(2), 128-35.

18. Bouchard C, Rankinen T. Individual diferences in response to regular physical activity. Med. Sci. Sports Exercise. 2001;33, 446-451.

19. Mustelin L, et al. Acquired obesity and poor physical fitness impair expression of genes of mitochondrial oxidative phosphorylation in monozygotic twins discordant for obesity. Am. J. Physiol. Endocrinol. Metab. 2008;295(1), E148-54. 
20. Ooki S, Asaka A. Zygosity diagnosis in young twins by questionnaire for twins' mothers and twins' self-reports. Twin Res Hum Genet. 2004;7(1), 5-12.

21. Del Valle HB, Yaktine AL, Taylor CL, Ross AC. Dietary reference intakes for calcium and vitamin D. National Academies Press, 2011.

22. Holick MF, Binkley NC, Bischoff-Ferrari HA, Gordon CM, Hanley DA, Heaney RP, Weaver CM. Evaluation, treatment, and prevention of vitamin D deficiency: an Endocrine Society clinical practice guideline J ClinEndocrinolMetab, 2011;96(7), 1911-1930.

23. Shechtman O, Gestewitz L, Kimble C. Reliability and validity of the DynEx dynamometer. J Hand Ther, 2005;18(3), 339-47.

24. Thompson WR, Gordon NF, Pescatello LS. ACSM's guidelines for exercise testing and prescription. Hubsta Ltd, 2009.

25. Beiguelman, B. The study of twins. 1th (ed. Ribeirão, P), São Paulo, 2008;20-22.

26. Schutte NM, Nederend I, Hudziak JJ, Bartels M, de Geus EJ. Twin-sibling study and meta-analysis on the heritability of maximal oxygen consumption. Physiological genomics. 2016;48(3), 210-9..

27. Jermendy G, Horvath T, Littvay L, Steinbach R, Jermendy A, Tarnoki A, et al. Effect of genetic and environmental influences on cardiometabolic risk factors: a twin study. Cardiovascular Diabetology. 2011;10(1), 96.

28. Pang, Z., Zhang, D., Li, S., Duan, H., Hjelmborg, J., Kruse, T. A. Tan, Q. Multivariate modelling of endophenotypes associated with the metabolic syndrome in Chinese twins. Diabetologia. 2010; 53(12), 2554-2561.

29. Tarnoki, A. D., Tarnoki, D. L., \& Molnar, A. A. Past, present and future of cardiovascular twin studies. Coret Vasa. 2014.

30. Kodama S, Saito K, Tanaka S, et al. Cardiorespiratory fitness as a quantitative predictor of all-cause mortality and cardiovascular events in healthy men and women. JAMA. 2009;301, 2024.

31. Hung RK, Al-Mallah MH, McEvoy JW, et al. Prognostic value of exercise capacity in patients with coronary artery disease: the FIT (Henry Ford Exerclse Testing) project. Mayo Clin Proc. 2014;89, 16441654.

32. Anderssen SA, Cooper AR, Riddoch C, et al. Low cardiorespiratory fitness is a strong predictor for clustering of cardiovascular disease risk factors in children independent of country, age and sex. Eur J CardiovascPrevRehabil. 2007;14, 526-531. 
33. Binder RK, Wonisch M, Corra U, Cohen-Solal A, Vanhees L, Saner H, et al. Methodological approach to the first and second lactate threshold in incremental cardiopulmonary exercise testing. European journal of cardiovascular prevention \& rehabilitation. 2008;15(6), 726-34.

34. Pitz S, März W, Wellnitz B, Seelhorst U, FahrleitnerPammer A. Association of vitamin D deficiency with heart failure and sudden cardiac death in a large cross-sectional study of patients referred for coronary angiography. J ClinEndocrinolMetab. 2008;93(10), 3927-935.

35. Gallagher JC. The effects of calcitriol on falls and fractures and physical performance tests. J Steroid BiochemMol Biol. 2014;89-90, 497-501.

36. Li YC, Qiao G, Uskokovic M, Xiang W, Zheng W, Kong J. Vitamin D: a negative endocrine regulator of the renin-angiotensin system and blood pressure. J Steroid BiochemMol Biol. 2004;89-90(1-5), 38792.

37. Simpson RU, Hershey SH, Nibbelink KA. Characterization of heart size and blood pressure in the vitamin D-receptor-knockout mouse. J Steroid BiochemMol Biol. 2007;103, 521-4.

38. Glerup H, Mikkelsen K, Poulsen L. Hypovitaminosis D myopathy without biochemical signs of osteomalacic bone involvement. Calcif Tissue Intern. 2000;66, 419-24.

39. Dawson-Hughes B. Vitamin D and muscle function. J Steroid BiochemMol Biol. 2017.

40. Ghose RR. Vitamin D deficiency and muscle weakness in the elderly. The New Zealand medical journal. 2005;118(1219), U1582.

41. Germain CM, Batsis JA, Vasquez E, McQuoid DR. Muscle Strength, Physical Activity, and Functional Limitations in Older Adults with Central Obesity. Journal of aging research. 2016;2016, 8387324.

42. Kraschnewski JL, Sciamanna CN, Ciccolo JT, Rovniak LS, Lehman EB, Candotti C, et al. Is exercise used as medicine? Association of meeting strength training guidelines and functional limitations among older US adults. Preventive medicine. 2014;66, 1-5.

43. Bouillon R. Can vitamin D prevent falls and fractures? The lancet Diabetes and endocrinology. 2017;5(6), 407-9.

44. Menant JC, Weber F, Lo J, Sturnieks DL, Close JC, Sachdev PS, et al. Strength measures are better than muscle mass measures in predicting healthrelated outcomes in older people: time to abandon the term sarcopenia? Osteoporosis international. 2017;28(1), 59-70.

45. Stessman J, Rottenberg Y, Fischer M, Hammerman-Rozenberg A, Jacobs JM. Handgrip Strength in Old and Very Old Adults: Mood, Cognition, Function, and Mortality. J Am Geriatr Soc. 2017;65(3), 52632. 
46. Chaturvedi V. Grip strength and mortality. NatIMed J India. 2015;28(6), 287-9.

47. Macera CA. Muscular strength and mortality in men. Clin J Sport Med. 2009;19(2), 150-1.

48. Mokta J, Mokta K, Ranjan A, Muruganathan A. Vitamin D and Muscle Weakness. J Assoc Physicians India. 2017;65(7), 116.

50. Orces $\mathrm{CH}$. Prevalence of clinically relevant muscle weakness and its association with vitamin D status among older adults in Ecuador. Aging ClinExp Res. 2017;29(5), 943-9.

51. Zhu K, Austin N, Devine A, Bruce D, Prince RL. A randomized controlled trial of the effects of vitamin D on muscle strength and mobility in older women with vitamin D insufficiency. J Am Geriatr Soc. 2010;58(11), 2063-8.

52. Cangussu LM, Nahas-Neto J, Orsatti CL, Bueloni-Dias FN, Nahas EA. Effect of vitamin D supplementation alone on muscle function in postmenopausal women: a randomized, double-blind, placebo-controlled clinical trial. Osteoporosis international. 2015.

53. Frederiksen H, Hjelmborg J, Jakob MMM, Vaupel JW, Christensen K. Age Trajectories of Grip Strength: Cross-sectional and Longitudinal Data Among. 2006;8(342), 102.

54. Desrosiers J, Hébert R, Bravo G, Rochette A. Age-related changes in upper extremity performance of elderly people: A longitudinal study. Experimental Gerontology. 1999;34, 393-405.

55. Alvares DSMR, Silveira TR. Hand-grip strength or muscle mass in cirrhotic patients: Who is the best? Nutrition. 2006;22, 218-219.

56. Cetinus E, Buyukbese MA, Uzel M, Ekerbicer H, Karaoguz A. Hand grip strength in patients with type 2 diabetes mellitus. Diabetes Res. Clin. Pract. 2005;70, 278-286.

57. Hornby ST, Nunes QM, Hillman TE, Stanga Z, Neal KR, Rowlands BJ, Allison SP, Lobo DN. Relationships between structural and functional measures of nutritional status in a normally nourished population. Clin. Nutr. 2005;24, 421-426.

58. Haidar SG, Kumar D, Bassi RS, Deshmukh SC. Average versus maximum grip strength: which is more consistent? J Hand Surg Am. 2004;29B(1), 82-84.

59. Hillman TE, Nunes QM, Hornby ST, Stanga Z, Neal KR, Rowlands BJ, Allison SP, Lobo DN. A practical posture for hand grip dynamometry in the clinical setting. Clin Nutri. 2005;24, 224-228.

60. Schlüssel MM, Anjos LAD, Kac G. Manual dynamometry and its use in nutritional assessment. Nutrition Magazine. 2008;21(2), 233-235.

61. Luna HE, Martín PG, Ruiz GJ. Handgrip dynamometry in healthy adults. Clin Nutri. 2005;24, 250-258. 
62. Armstrong CA, Oldham JA. A comparison of dominant and non-dominant hand strengths. J Hand Surg. 1999;24(4), 421-415.

63. Mitsionis G, Pakos EE, Stafilas KS, Paschos N, Papakostas T, Beris AE. Normative data on hand grip strength in a Greek adult population. IntOrthop. 2009;33(3), 713-717.

64. Chiang, Chien-ming et al. Effects of Vitamin D Supplementation on muscle strength in athletes: a systematic review. The Journal of Strength \& Conditioning Research. 2017;31(2),566-574.

\section{Tables}

Table 1. Family income and physical activity levels in monozygotic twins.

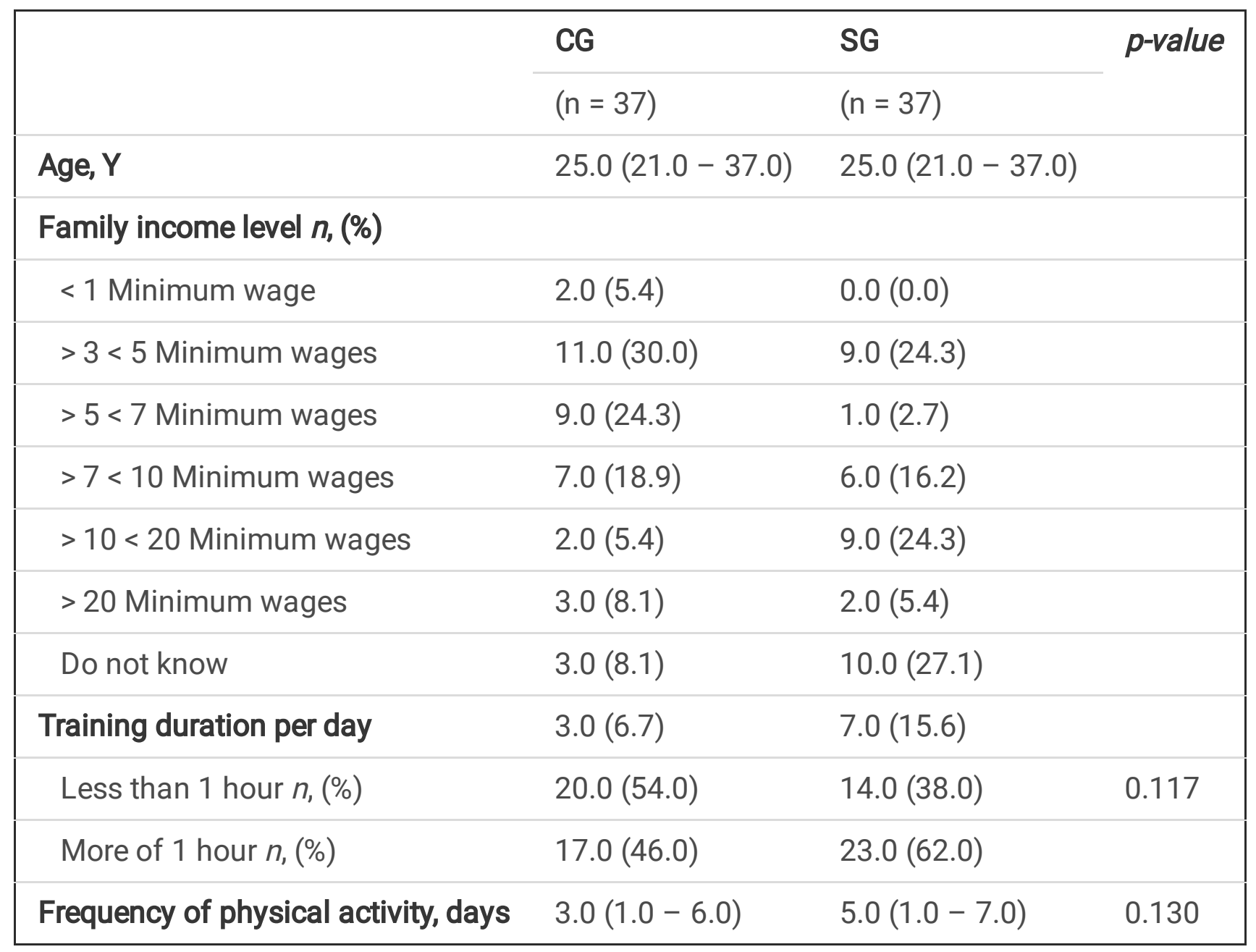

Categorical variables are shown as number (percentage) and compared by Chi-square test. Continuous variables are shown as median (minimum and maximum). CG, Control group; SG, Supplemented group. Brazilian minimum wage per month $=$ US $\$ 265.73$. $p$-value $<0,05$ were considered significant.

Table 2. Cardiorespiratory fitness and muscle strength in monozygotic twins after supplementation with cholecalciferol. 


\begin{tabular}{|c|c|c|c|c|c|c|}
\hline & \multicolumn{2}{|c|}{ Control group $(n=37)$} & \multirow{2}{*}{$\begin{array}{l}p- \\
\text { value }\end{array}$} & \multicolumn{2}{|c|}{$\begin{array}{l}\text { Supplemented group }(n= \\
37 \text { ) }\end{array}$} & \multirow{2}{*}{$\begin{array}{l}p- \\
\text { value }\end{array}$} \\
\hline & TO & T60 & & TO & T60 & \\
\hline $\begin{array}{l}\mathrm{VO}_{2} \text { max absolute, } \mathrm{l} / \\
\text { min }\end{array}$ & $\begin{array}{l}2.2(1.8- \\
2.6)\end{array}$ & $\begin{array}{l}2.1(1.2- \\
2.4)\end{array}$ & 0.359 & $\begin{array}{l}2.0(1.6- \\
2.6)\end{array}$ & $\begin{array}{l}2.6(2.1- \\
3.2)\end{array}$ & $\dot{0} 001$ \\
\hline $\begin{array}{l}\mathrm{VO}_{2} \text { max relative, } \\
\mathrm{ml} / \mathrm{kg}^{-1} / \mathrm{min}^{-1}\end{array}$ & $\begin{array}{l}34.5(31.0 \\
-40.0)\end{array}$ & $\begin{array}{l}34.5(31.0- \\
40.8)\end{array}$ & 0.414 & $\begin{array}{l}33.5(29.0 \\
-38.8)\end{array}$ & $\begin{array}{l}33.5(29.3 \\
-47.0)\end{array}$ & 0.118 \\
\hline RER max & $\begin{array}{l}1.1(1.0- \\
1.2)\end{array}$ & $\begin{array}{l}1.1(1.1- \\
1.2)\end{array}$ & 0.098 & $\begin{array}{l}1.1(1.0- \\
1.2)\end{array}$ & $\begin{array}{l}1.1(1.0- \\
1.1)\end{array}$ & 0.071 \\
\hline Right Hand Grip, kgf & $\begin{array}{l}32.5(29.5- \\
38.0)\end{array}$ & $\begin{array}{l}36.0(31.0- \\
37.0)\end{array}$ & 0.631 & $\begin{array}{l}32.0(28.5- \\
39.0)\end{array}$ & $\begin{array}{l}34.0(29.0- \\
40.0)\end{array}$ & 0.163 \\
\hline Left Hand Grip, kgf & $\begin{array}{l}29.0(25.3- \\
38.0)\end{array}$ & $\begin{array}{l}31.0(27.0- \\
37.3)\end{array}$ & 0.606 & $\begin{array}{l}28.0(24.0- \\
32.5)\end{array}$ & $\begin{array}{l}33.0(29.0- \\
40.5)\end{array}$ & 0.007 \\
\hline Scapular Force, kgf & $\begin{array}{l}23.0(19.5- \\
28.0)\end{array}$ & $\begin{array}{l}23.0(18.5- \\
28.3)\end{array}$ & 0.952 & $\begin{array}{l}24.0(17.5- \\
30.0)\end{array}$ & $\begin{array}{l}23.0(18.8- \\
28.3)\end{array}$ & 0.441 \\
\hline
\end{tabular}

Variables are shown as median (percentile 25 - percentile 75) and compared by Wilcoxon test. $\mathrm{VO}_{2}$ max, Maximum oxygen consumption; RER max, Respiratory exchange ratio; CG, Control group; SG, Supplemented group; T0, first analysis; T60, analysis 60 days after the first. $p$-value $<0,05$ were considered significant.

\section{Figures}

\section{Image not available with this version}

\section{Figure 1}

Flowchart illustrating the selection of the study population 